\title{
ASO Visual Abstract: Debate: Postmastectomy Radiation Therapy in T1/2N1 Disease
}

\author{
Anees B. Chagpar, MD, MSc, MPH, MA, MBA \\ Department of Surgery, Yale University School of Medicine, New Haven, CT
}

As discussed in the source article for this Visual Abstract (https://doi.org/10.1245/s10434-021-10500-5), although both radiation and surgery have some toxicity, both methods also confer some benefit in terms of local control. The question then is how therapy can be optimally de-escalated and for whom. Current ongoing clinical trials have been designed to provide some insight into this question. Until these trials are completed, this topic remains controversial.
Publisher's Note Springer Nature remains neutral with regard to jurisdictional claims in published maps and institutional affiliations.

\section{Right Sizing Radiation Therapy After Mastectomy}

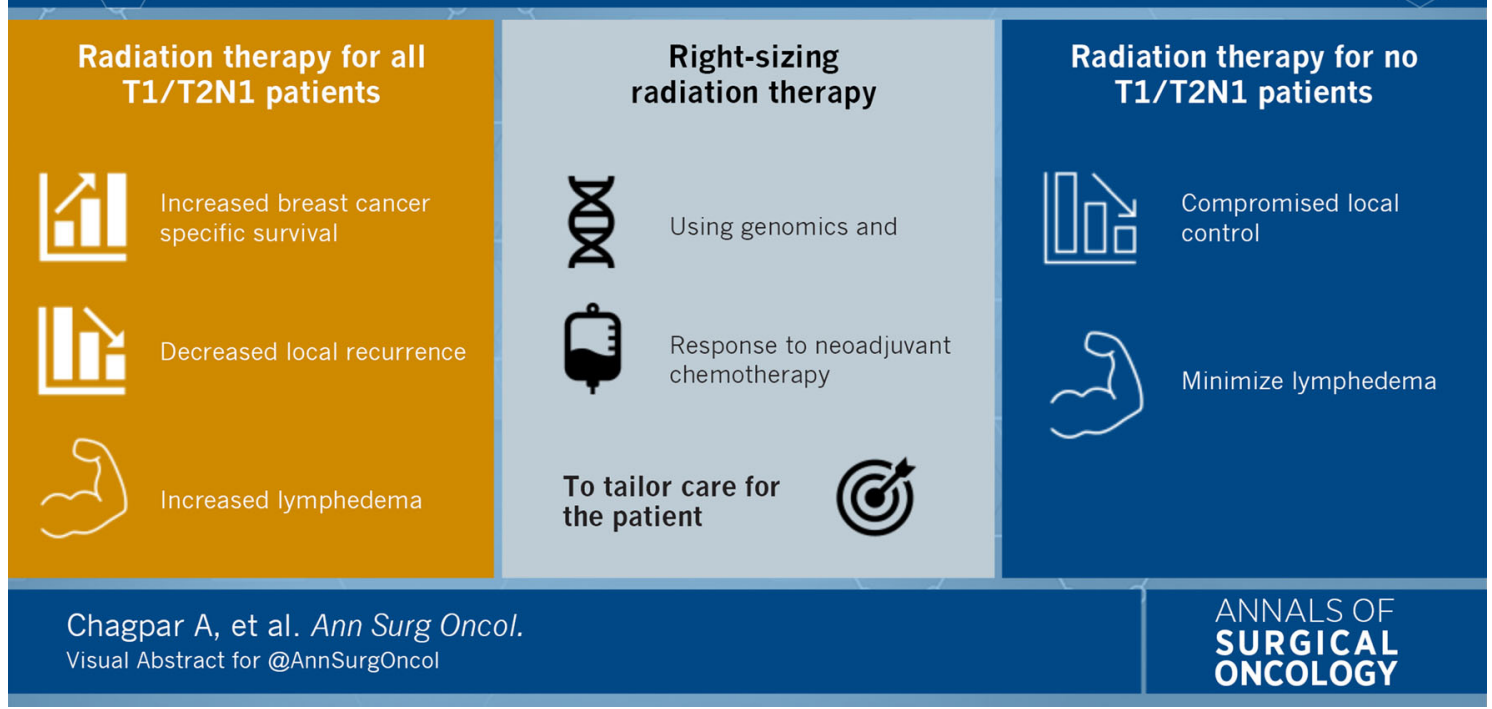

(C) Society of Surgical Oncology 2021

Published Online: 25 August 2021

A. B. Chagpar, MD, MSc, MPH, MA, MBA

e-mail: anees.chagpar@yale.edu 